\title{
As estratégias de cuidados para o alívio dos efeitos colaterais da quimioterapia em mulheres
}

\author{
Leonardo Magela Lopes Matoso', Sâmara Sirdênia Duarte de Rosário², Mônica Betania Lopes Matoso³
}

\begin{abstract}
RESUMO
Objetivo: compreender a partir da percepção das mulheres que realizam quimioterapia, as estratégias de cuidados utilizadas pela equipe de enfermagem na redução e/ou alívio dos efeitos colaterais causados pelo tratamento quimioterápico. Metodologia: estudo de natureza descritiva, exploratória, com abordagem qualitativa. A coleta ocorreu em um centro de oncologia em uma cidade no interior do Rio Grande do Norte - RN, através de um roteiro de entrevista semiestruturado. Os dados foram analisados com a técnica do Discurso do Sujeito Coletivo. Resultados: a enfermagem orienta quanto às questões alimentares, proteção do corpo, quanto a não frequentar ambientes fechados e os medicamentos recomendados sobre prescrição médica. Conclusão: observou-se a importância das orientações de enfermagem direcionadas a este público, para o enfrentamento das reações adversas decorrentes do tratamento quimioterápico e, conseqüentemente, melhoria nos padrões de qualidade de vida.
\end{abstract}

Descritores: Enfermagem Oncológica; Farmacoterapia; Efeitos Adversos..

\section{The care strategies for alleviating side effects of chemotherapy in women}

\begin{abstract}
Objective: to understand from the perception of women undergoing chemotherapy, the care strategies used by the nursing staff in reducing and I or alleviating side effects caused by chemotherapy. Methodology: Study descriptive, exploratory, qualitative approach. The collection took place in an oncology center in a city in the interior of Rio Grande do Norte - RN, through a semi-structured interview guide. Data were analyzed with the technique of the Collective Subject Discourse. Results: nursing as guides to food issues, body protection, as to not go indoors and recommended medicines on prescription. Conclusion: noted the importance of nursing instructions targeted at these children, to cope with adverse reactions to the chemotherapy and, consequently, to improve the standards of quality of life.
\end{abstract}

Descriptors: Oncology Nursing; Chemotherapy; Adverse Effects.

${ }^{1}$ Enfermeiro graduado pela Universidade Potiguar (UnP), Mossoró, RN, Brasil.

${ }^{2}$ Mestre em Enfermagem pela Universidade Federal do Rio Grande do Norte (UFRN), Caicó, RN, Brasil.

${ }^{3}$ Especialista em Pluralidade Cultural e Orientação Sexual pela Universidade do Estado do Rio Grande do Norte (UERN), Pau dos Ferros, RN, Brasil. 


\section{Introdução}

A palavra câncer inclui muitas designações de doenças caracterizadas pelo desenvolvimento de células que perderam sua capacidade de crescimento normal e, assim, sofreram multiplicação e proliferam desordenadas, no local ou à distância'

De acordo com estudos realizados pelo Instituto Nacional de Câncer (INCA), os anos de 2012 e 2013, conta com um índice de aproximadamente 518.510, incluindo os casos de pele não melanoma, reforçando a magnitude do problema do câncer no país. Sem os casos de câncer da pele não melanoma, estima-se um total de 385 mil casos novos².

Os tratamentos utilizados para o combate das neoplasias são cirurgia, radioterapia, terapia hormonal, imunoterapia e quimioterapia, podendo ser utilizado isoladamente ou em combinação ${ }^{3}$.

A quimioterapia consiste no uso de drogas citotóxicas que devem ser administradas preferencialmente combinadas, a fim de atuarem em fases diferentes da divisão celular, destruindo as células que apresentam uma disfunção no seu processo de crescimento ou divisão. Devido a sua inespecificidade em relação às células que são alvo, as drogas antineoplásicas podem atingir células normais, principalmente, aquelas que se renovam constantemente, causando reações adversas ${ }^{4}$.

A quimioterapia proporciona o aumento da sobrevida livre da doença, uma vez que é um tratamento que promove o controle ou a erradicação de micrometástases. Porém, essa terapêutica está associada a efeitos colaterais, muitas vezes, agressivos que podem conduzir a mulher a alterações na sua autoestima, perda funcional, além de alterações emocionais e sociais. Por isso é realizada em ciclos com intervalos determinados para que as células normais não sejam bastante prejudicadas durante 0 tratamento ${ }^{1}$.

Diante disso, é válido indagar: Quais as estratégias de cuidados realizadas pela equipe de enfermagem na redução e/ ou alívio dos efeitos colaterais causados pelo tratamento quimioterápico em mulheres em um centro de oncologia?

Este estudo justifica-se, pelo fato dos efeitos colaterais causarem danos físicos e psicológicos às pacientes, debilitando o estado geral de saúde. Para cada alteração, é necessário que a paciente seja orientada e incentivada a participar de forma consciente na tomada de decisão sobre as medidas de autocuidado, visando à redução do impacto da doença, através da criação de hábitos saudáveis durante o tratamento ${ }^{4}$.

Nesta perspectiva, é relevante apontar a necessidade de se trabalhar essa temática tendo em vista que a discussão dos efeitos colaterais da quimioterapia em mulheres é considerada significante para a oncologia, para a família, e principalmente para a mulher. Pois alguns efeitos colaterais como a queda de cabelos, distorcem sua autoimagem causando negação ao tratamento de quimioterapia, depressão e até privação nas relações sociais ${ }^{4}$.

Sendo assim, o objetivo geral deste estudo é compreender a partir da percepção das mulheres que realizam quimioterapia, as estratégias de cuidados realizadas pela equipe de enfermagem na redução e/ou alívio dos efeitos colaterais causados pelo tratamento quimioterápico.

Os objetivos específicos foram identificar os principais sinais e sintomas nas mulheres submetidas à quimioterapia; conhecer as principais estratégias de cuidados utilizados pela equipe de enfermagem para o alívio dos efeitos colaterais nas mulheres em tratamento oncológico; e propor a construção de uma cartilha sobre autocuidado acerca dos efeitos colaterais apresentados pela quimioterapia nas mulheres em tratamento no Centro de Oncologia e Hematologia de uma cidade no interior do Rio Grande do Norte - RN.

\section{Metodologia}

Trata-se de um estudo de caráter descritivo e exploratório com abordagem predominantemente qualitativa. A pesquisa qualitativa trabalha com o universo de significados, motivos, aspirações, crenças, valores e atitudes, o que responde a um espaço mais profundo das relações, dos processos e dos fenômenos que não podem ser reduzidos à operacionalização de variáveis ${ }^{5}$.

Assim, o cenário desse referido estudo foi um Centro de Oncologia e Hematologia localizado em uma cidade no interior do Estado do Rio Grande do Norte - RN, no qual é referência no atendimento à pacientes com câncer para o Município e as cidades circunvizinhas.

Participaram desse estudo oito mulheres em tratamento quimioterápico no Centro de Oncologia e Hematologia selecionadas através dos seguintes critérios de inclusão: mulheres portadoras de câncer; que estivessem realizando quimioterapia há mais de 10 dias; que fossem maiores de idade; que apresentassem algum efeito colateral, e que estivessem no local pesquisado no dia da coleta de dados a ser realizada pelos pesquisadores. Os critérios de exclusão foram subsidiados pelos critérios de inclusão. 
Utilizou-se como instrumento de coleta de dados uma entrevista com roteiro semiestruturado, que foi aplicado após a obtenção do parecer favorável do Comitê de Ética e Pesquisa da Universidade Potiguar sob número 126.289/2012.

Dada a proximidade do convívio com estas mulheres, e pela convicção que as informações deverão se repetir com frequência absoluta, optou-se devido à saturação dos dados, trabalhar com uma amostra de no máximo dez coparticipantes. O fechamento amostral por saturação dos dados se dá devido ao momento em que o acréscimo de dados e informações em uma pesquisa não altera a compreensão do fenômeno estudado ${ }^{6}$. Noutras palavras, as informações fornecidas pelos novos participantes da pesquisa pouco acrescentariam ao material já obtido, não mais contribuindo significativamente para o aperfeiçoamento da reflexão teórica fundamentada nos dados que estão sendo coletados.

As entrevistas foram realizadas dentro do setor de quimioterapia feminino, no qual as mulheres foram convidadas a participar do estudo através do contato direto antes da realização da quimioterapia. Para preservar a identidade das mesmas, utilizou-se em substituição aos nomes reais, nome de mulheres guerreiras que fizeram história no Brasil e no mundo, tais como: Anita Garibaldi, Cora Coraline, Cleópatra, Joana D’Arc, Ana Floriano, Olga Benário, Chiquinha Gonzaga e Carmen Miranda.

Os dados qualitativos foram analisados de acordo com a técnica do Discurso do Sujeito Coletivo (DSC) ${ }^{7}$ que é uma modalidade de apresentação de resultados de pesquisas qualitativas, que tem como matéria prima os depoimentos. Esses depoimentos foram apresentados sob a forma de um ou vários discursos - síntese escrita na primeira pessoa do singular visando expressar o pensamento de uma coletividade, como se esta coletividade fosse o emissor de um discurso ${ }^{7}$.

As expressões chave (ECH) são pedaços, trechos do discurso, que devem ser destacados pelo pesquisador, e que revelam a essência do conteúdo do discurso ou a teoria subjacente. A Ideia Central (IC) é um nome ou expressão linguística que revela, descreve e nomeia, da maneira mais sintética e precisa possível, o(s) sentido (s) presentes em cada uma das respostas analisadas e de cada conjunto homogêneo de $\mathrm{ECH}$, que vai dar nascimento, posteriormente, ao DSC. Algumas ECH remetem não apenas a uma IC correspondente, mas também e explicitamente a uma afirmação que denominamos Ancoragem (AC) que é a expressão de uma dada teoria ou ideologia que 0 autor do discurso professa e que está embutida no seu discurso como se fosse uma afirmação qualquer ${ }^{7}$.

\section{Resultados e Discussões}

\section{Quem sou eu?}

Fizeram parte deste estudo um grupo de oito mulheres que estão em tratamento quimioterápico em um Centro de Oncologia e Hematologia no Estado do Rio Grande do Norte.

A faixa etária das entrevistadas varia entre 22 a 76 anos de idade. Destas, quatro (50\%) são brancas, duas ( $25 \%$ ) são pardas e duas (25\%) são negras. Quanto ao estado civil, três (37,5\%) são viúvas, duas (25\%) separadas e três (37,5\%) solteiras. No que se refere à escolaridade, cinco (62,5\%) possuem nível médio, duas (25\%) fundamental incompleto e uma (12,5\%) fundamental completo. Das participantes, cinco (62,5\%) tem câncer de mama, duas (25\%) tem câncer de fígado e uma (12,5\%) câncer no rim esquerdo.

O câncer de mama foi o mais evidenciado neste estudo, com 62,5\% em mulheres com idade que variam de 24 a 52 anos. Autores referem ${ }^{8}$ que o câncer de mama possui uma incidência relativamente rara antes dos 35 anos, no entanto, pode-se evidenciar que nesse estudo $20 \%$ (1) possui idade inferior a esta, ou seja, 24 anos.

É possível evidenciar o perfil de cada uma das participantes no quadro a seguir:

Quadro 1 - Apresentação dos Sujeitos da Pesquisa:

\begin{tabular}{|c|c|c|c|c|c|}
\hline Participantes & Idade & Cor & Estado Civil & Escolaridade & Câncer \\
\hline Anita Garibaldi & 52 & Negra & Viúva & Nível Médio & Mama \\
\hline Cora Coraline & 41 & Parda & Separada & Fund. Incomp & Mama \\
\hline Cleópatra & 43 & Branca & Separada & Nível Médio & Mama \\
\hline Joana D'Arc & 22 & Branca & Solteira & Nível Médio & Fígado \\
\hline Ana Floriano & 60 & Branca & Viúva & Fund. Incomp & Fígado \\
\hline Olga Benário & 76 & Branca & Viúva & Fund. Comple & Rim \\
\hline Chiquinha Gon. & 24 & Negra & Solteira & Nível Médio & Mama \\
\hline Carmen Mira. & 45 & Parda & Solteira & Nível Médio & Mama \\
\hline
\end{tabular}

Fonte: Informação oriunda das participantes dessa pesquisa. 
Para a análise, os DSC foram agrupados por tema abordado. Cada DSC, foi associada à idéia central correspondente para que fosse possível analisar os depoimentos colhidos, utilizando-se a literatura científica atual sobre 0 assunto.

\section{$\underline{\text { Como eu descobri? }}$}

Quando questionadas sobre a descoberta da doença, os discursos apontaram duas ideias centrais: (1) Exames de Rotinas e (2) Sinais.

Quadro 2 - A descoberta da doença.

\begin{tabular}{|c|c|}
\hline Ideia Central & Discurso do Sujeito Coletivo \\
\hline (1) Exames de Rotina & $\begin{array}{c}\text { Descobri a doença através dos meus exames de } \\
\text { rotina durante a campanha do outubro rosa que uma } \\
\text { enfermeira fez (...) ai quando fui fazer uma vistoria } \\
\text { através da ultrassonografia a minha médica encontrou } \\
\text { problemas no meu fígado. Fiz exames e era câncer. }\end{array}$ \\
\hline (2) Sinais (caroço/ nódulo/sangue) & $\begin{array}{c}\text { Percebi um caroço duro na barriga (...) urinei e saiu } \\
\text { sangue (...) fui ao médico depois que percebi um } \\
\text { carocinho no bico do peito ai fiz os exames e foi } \\
\text { detectado câncer. }\end{array}$ \\
\hline
\end{tabular}

Fonte: Informação oriunda das participantes dessa pesquisa, ano 2013.

A primeira ideia central revela que os exames periódicos é uma ferramenta fundamental para a detecção precoce do câncer. A realização de exames de rotina é primordial, pois muitas vezes ocorre à descoberta da doença ainda na fase inicial, e o diagnostico precoce aumenta as chances de cura e minimiza a agressividade do tratamento.

A importância do diagnóstico precoce do câncer está em tentar evitar a disseminação das células malignas pelo corpo. Por isso, quando o mesmo é detectado e tratado precocemente a mulher tem mais opções de tratamento e boas chances de recuperação completa? .

Os discursos analisados na segunda ideia central mostram que a presença de caroço, nódulos e sangue, foi um sinal considerado como indicativo de doença. $\mathrm{O}$ que fez com que as mulheres buscassem um profissional qualificado para detectar a presença desses sinais e traçar uma diagnose precisa.

$\mathrm{Na}$ ótica de alguns autore $\mathrm{s}^{10}$ as mulheres percebem alterações em seus corpos, e automaticamente fazem suposições, sendo esse momento vivenciado de modo muito singular. O processo de descoberta da doença tem início quando a mulher detecta que algo se encontra modificado em seu corpo. Nos discursos, a maioria das mulheres revela terem descoberto o câncer de maneira inusitada, por acaso, ou seja, sem que elas estivessem desconfiando de algum problema de saúde.

A percepção que as pessoas têm das alterações físicas quando estão doentes geralmente representa o primeiro estágio do adoecimento, sendo necessário investigar. Foi o que aconteceu com o publico alvo desta pesquisa, que ao perceber as manifestações físicas como sinais indicativos de possível adoecimento, foram instigadas a procurar 0 médico e tiveram seu diagnostico confirmado ${ }^{11}$.

Diante da segunda ideia central, merece destaque, a afirmativa de uma das mulheres, diante da conduta médica realizada na atenção básica em saúde:

"Eu notei um carocinho no bico do peito. Fui ao médico da UBS que disse que não era nada demais. Quando sai da sala dele, a Agente Comunitária de Saúde me perguntou 0 que ele tinha dito e disse que eu procurasse um especialista, ela mesma me indicou e dias depois eu fui atrás. Quando fiz os exames deu câncer de mama. - Cora Coraline".

De acordo com a Politica Nacional de Atenção Básica (PNAB), são atribuições comuns a todos os profissionais de saúde, participar do acolhimento dos usuários realizando a escuta qualificada das necessidades de saúde, procedendo à primeira avaliação (classificação de risco, avaliação de vulnerabilidade, coleta de informações e sinais clínicos) e identificação das necessidades de intervenções de cuidado, proporcionando atendimento humanizado, responsabilizandose pela continuidade da atenção e viabilizando o estabelecimento do vínculo². 
No entanto, segundo relato da participante o médico afirmou que era normal à alteração na sua mama, devido à mesma ter amamentado por muito tempo. No Brasil, segundo o INCA, muito ainda tem que ser feito para que os médicos assumam a responsabilidade que lhes cabem quanto à prevenção, diagnóstico e ao controle do câncer. Aadequação das condutas diagnósticas e terapêuticas, e agilidade no encaminhamento do caso constituem o âmago do exercício efetivo de tal responsabilidade ${ }^{1 ; 2}$.

\section{Como eu me Sinto?}

Em relação aos sentimentos das mulheres sobre a realização do tratamento quimioterápico, pode-se dividir esta categoria em três ideais centrais: péssima, ruim e mal; poucas reações e ótima.

Quadro 3 - Como se sente ao realizar o tratamento de quimioterapia?

\begin{tabular}{|c|c|}
\hline Ideia Central & Discurso do Sujeito Coletivo \\
\hline (1) Péssima, Ruim, Mal & $\begin{array}{r}\text { Péssima. Preferia fazer } 10 \text { mil cirurgias a uma quimioterapia. A quimioterapia é } \\
\text { uma droga que praticamente acaba com você. É horrível (...) tem muitos efeitos } \\
\text { colaterais. Sem contar que sinto medo. Quando descobri a doença me senti } \\
\text { destruída e a quimioterapia me deixa muito pra baixo. Sem contar que tiver } \\
\text { alergia, dores, vomito e náuseas. }\end{array}$ \\
\hline (2)Poucas reações & $\begin{array}{r}\text { Me sinto mais ou menos (...) só assim, um pouquinho de enjoo, os olhos } \\
\text { apertando um pouco, ardendo como se eu quisesse ir dormir. Não tive } \\
\text { náuseas, não tive queda de cabeço, não tive dor de barriga, eu não tive nada } \\
\text { que as outras tiveram. No começo eu engordei muito, só isso. }\end{array}$ \\
\hline (3) Ótima & $\begin{array}{c}\text { Com relação às outras eu estou ótima, pois só sinto dor de cabeça e meus } \\
\text { cabelos caíram com 15 dias depois da primeira quimioterapia. }\end{array}$ \\
\hline
\end{tabular}

Fonte: Informação oriunda das participantes dessa pesquisa, ano 2013.

Na primeira idéia central pode-se evidenciar o medo que as mulheres sentem em relação à quimioterapia e até mesmo ao câncer, pois a pessoa acometida pela doença vive a descoberta do diagnóstico e todo o processo de tratamento com intensa angústia, sofrimento e ansiedade. Além do rótulo que a doença carrega, sendo está dolorosa e mortal. Essas mulheres comumente vivenciam no tratamento sintomas adversos, acarretando prejuízos nas habilidades funcionais e incerteza quanto ao futuro'.

Pesquisas evidenciam ${ }^{4}$ que a terapêutica pode ser extremamente agressiva, acarretando inúmeros efeitos colaterais, assim como, impactos psicoemocional. E nesse processo são comuns as pacientes se sentirem desanimadas, indispostos e por tanto muita das vezes péssimas enquanto pessoa.

Em contrapartida, a segunda ideia central, mostra que os efeitos colaterais da quimioterapia apresentam-se de forma singular para cada indivíduo, alguns com maior potencial danoso e outros com menor grau de agressividade, pois as depoentes afirmaram se sentirem mais ou menos, queixando-se apenas de alguns enjoos, sonolência e aumento de peso.

No que se refere à terceira ideia central, a depoente revela sentir-se ótima em relação às demais colegas que realizam quimioterapia, mesmo sofrendo de dores de cabeça que não são muito frequentes e da queda de cabelo. Aqueda de cabelo pode ter efeito devastador para algumas mulheres, por representar um indicador visível da doença e desfigurar a imagem feminina ${ }^{12}$.

\section{$\underline{\text { Oque mais me incomoda? }}$}

Ao se referirem ao assunto em questão, as entrevistadas apontaram quatro idéias centrais: Dor; Falta de animo, sonolência, fadiga; Dificuldade de aceitação da autoimagem e Náuseas e Vômitos. 
Quadro 4 - O que mais incomoda em relação a esses efeitos sentidos? E com que frequência eles surgem?

\begin{tabular}{|c|c|}
\hline Ideia Central & Discurso do Sujeito Coletivo \\
\hline (1) Dor & $\begin{array}{c}\text { (...) È o apertozinho na cabeça, me sinto dopada. Costuma } \\
\text { aparecer às vezes. (...) Tem também essa dor nos ossos, tem } \\
\text { dias que arroxa mesmo ai eu não ando, passo o dia deitada. } \\
\text { Surge às vezes, geralmente depois da QT. }\end{array}$ \\
\hline (2) Falta de animo, sonolência, fadiga. & $\begin{array}{c}\text { Assim (...) o que mais me incomoda é falta de vontade, de } \\
\text { animo, fico querendo dormir direto sabe? A pior coisa é você } \\
\text { ter vontade de curtir a vida e não ter como. Frequentemente eu } \\
\text { sinto isso. Eu fico muito pra baixo. }\end{array}$ \\
\hline (3) Dificuldade de aceitação da \\
autoimagem & $\begin{array}{c}\text { O que mais incomoda é a gordura, eu estou ficando muito } \\
\text { gorda (...) e eu como muito. Tem também a queda de cabelo, } \\
\text { eu uso os lenços, mas me sinto feia, sei lá. Não gosto. Isso } \\
\text { aparece frequentemente. }\end{array}$ \\
\hline (4) Náuseas e Vômitos & $\begin{array}{c}\text { O que mais me incomoda são as náuseas e o vomito, surge de } \\
\text { vez em quando, é péssimo. }\end{array}$ \\
\hline
\end{tabular}

Fonte: Informação oriunda das participantes dessa pesquisa, ano 2013.

Na primeira ideia central pode-se evidenciar que a dor é algo muito marcante e que está presente em quase todas as entrevistadas, algumas com maior potencial, outras não. A dor é uma sensação ou experiência emocional desagradável, associada com dano tecidual real ou potencial, ou descrita nos termos de tal dano, sendo esta, sempre subjetiva e pessoal ${ }^{13}$.

De acordo com alguns pesquisadores ${ }^{14}$, devido às drogas antineoplásicas serem inespecíficas, pode levar a diversos efeitos colaterais, principalmente, em células de reprodução rápida, como as da medula óssea, mucosa intestinal e folículos pilosos. Tais efeitos podem modificar a vida dos pacientes, fazendo com que a terapêutica seja interpretada como a perda do controle da vida muitas vezes por ser dolorosa.

Alguns tipos de quimioterapias que podem provocar efeitos secundários como ardor, formigamento, lesões na boca, dor de cabeça, dores nas mãos, pés, musculares e/ou de estômago. Esses efeitos são causados tanto pela doença quanto pelo tratamento quimioterápico".

A falta de animo, sonolência e fadiga na segunda ideia central são complicações mais frequentes associadas ao câncer e ao seu tratamento, particularmente à quimioterapia. A sensação costuma ser descrita pela maioria dos pacientes como um estado constante de letargia e fraqueza, cansaço, indisposição, sonolência, falta de ânimo e de energia. A anemia é um efeito colateral comum que também pode levar à fadiga ou agravá-la.

A terceira ideia central mostra que o tratamento quimioterápico pode produzir grandes sequelas na autoestima dependendo do procedimento adotado, devido às reações do tratamento como mal-estar, queda de cabelo, ganho de peso, alterações da coloração da pele, entre outros, contribuindo assim, para sensação de vulnerabilidade e inaptidão física, o que acaba refletindo na dificuldade de aceitação da autoimagem.

Com relação à quarta ideia central, pesquisas revelam ${ }^{1}$ que as náuseas e os vômitos são eventos adversos da quimioterapia que implicam em complicações metabólicas graves e comprometem a adesão do tratamento, levando até mesmo ao abandono.

É importante ressaltar que cabe a enfermagem desenvolver ações de educação em saúde durante a permanência das mulheres no ambulatório, a fim de favorecer uma melhor adaptação ao tratamento e promover o bem estar das pacientes, pois possuem um maior contato com estas, além de fazer parte do papel da enfermagem, a educação em saúde.

\section{Como a enfermagem cuida?}

Quando indagadas acerca das condutas da equipe de enfermagem em relação aos efeitos colaterais, foram unanime os relatos sobre as orientações relacionadas à alimentação, proteção do corpo, a frequência á ambientes fechados e medicalização conforme prescrição médica. 
Quadro 5 - Quais condutas à equipe de enfermagem fazem em relação a esses efeitos colaterais?

\begin{tabular}{|c|c|}
\hline Ideia Central & Discurso do Sujeito Coletivo \\
\hline (1) Orientações & Elas explicam tudo. Manda fazer uma dieta saudável e me \\
& deram uma apostilha que contemplava algumas coisas \\
como: não sair em locais com muita gente, usar mascara, \\
hidratantes, que não devemos comer nada carregado \\
também. Diz que quando sentir, coisas assim, pesadas, mais \\
forte, ligue pra cá, pra falar com o médico pra eles ficarem \\
sabendo o que esta acontecendo, se tiver como eles vão lá \\
na casa da gente (...) Disse que era normal sentir algumas \\
coisas, que tomasse os remédios que o medico receitou e \\
caso não passasse comunicasse o medico ou procurasse \\
uma UPA ou centro de oncologia. \\
\hline
\end{tabular}

Fonte: Informação oriunda das participantes dessa pesquisa, ano 2013.

Sabe-se que o profissional de enfermagem é, na área da saúde, aquele que permanece mais tempo junto ao paciente, e nesse caso especifico, aos pacientes oncológico. Pelas próprias características de sua atuação, este tem durante suas atividades cotidianas, como contribuir para auxiliar durante o tratamento, proporcionando conforto através da assistência, diminuindo a ansiedade e o medo dos pacientes. Acredita-se que, através desse modo de cuidar, propicia-se ao outro a percepção de que existe nele uma força, uma pulsão de vida, uma vontade, que quando acionada, é capaz de gerar transformações ${ }^{15}$.

Nesse sentido, é de suma importância o papel do profissional de enfermagem quanto aos efeitos colaterais dos pacientes acometidos pela quimioterapia, tais como: orientação acerca dos cuidados com a pele (uso de bloqueadores, protetores solares e hidratantes), evitar aglomerações e contato com pessoas doentes, manter boa higiene oral e corporal, alimentação (encaminhar ao nutricionista e/ou alerta-los quanto a importâncias de alguns alimentos na dieta), uso dos medicamentos recomentados pelo especialista, entre outros.

Os efeitos colaterais podem ser uma das principais limitações do tratamento. Assim, cabe lembrar que alguns pacientes podem apresentar efeitos colaterais mais severos enquanto outros podem apresentar efeitos mais amenos, até mesmo não apresentar sintoma algum. Das orientações realizadas pela enfermagem, a mais enfática trata-se das orientações medicamentosas, como o uso de antieméticos, por exemplo.

Para prevenção e manejo das náuseas e vômitos, sintomatologia muito presente como efeito colateral da quimioterapia é de suma importância à utilização desse medicamento, uma vez que em nosso estudo as náuseas e vômitos são os efeitos colaterais mais frequentes em nossas entrevistadas, causando desgaste muito grande as mesmas.

Sendo assim, cabe ao enfermeiro indicar e fornecer orientações relativas às medidas preventivas, identificar precocemente os efeitos colaterais do tratamento a fim de minimizá-los, orientar e acompanhar a paciente e respectiva família e manter em mente que as ações de enfermagem devem ser individualizadas, considerando suas características pessoais e sociais. É de grande ajuda a disponibilização de orientações gerais na forma impressa, pois este recurso auxilia no processo de orientação e esclarecimento da própria mulher e de seus familiares. Ele permite reforçar e garantir acesso fácil às orientações fornecidas durante a consulta de enfermagem ${ }^{16}$.

Os familiares das pacientes também necessitam de orientação quanto aos sintomas mais comuns apresentados durante o tratamento quimioterápico para que possam prestar cuidados da forma mais adequada possível ${ }^{16}$.

O enfermeiro ao está envolvido no processo de cuidado a pacientes em tratamento de quimioterapia, tem a possibilidade de promover os cuidados específicos ao paciente durante e apos as sessões. A fim de organizar a prestação desta assistência podese utilizar o processo de enfermagem (PE), no qual oferece uma forma logica, sistêmica e racional de organizar informações ${ }^{17}$.

A ação educativa com os pacientes em tratamento com quimioterapia se faz essencial, pois através desta os pacientes estarão aptos para apreenderem a viver dentro de suas limitações, de uma maneira que não seja controvérsia ao modo de vida, conseguindo assim atingir uma convivência com a doença e com o seu tratamento. É necessário identificar suas particularidades e necessidades, auxiliando-os a alcançar um sentimento de autonomia e sentindo-se responsáveis pelo seu autocuidado, para que assim sejam capazes de assumir o controle de seus esquemas de tratamento ${ }^{16}$. 
Sendo assim, a atuação do enfermeiro se faz indispensável, pois é o profissional que estará em contato direto com a paciente, sua família e o restante da equipe de saúde, sendo imprescindível que ele utilize a sua comunicação terapêutica de uma maneira mais apropriada, visando à compreensão e o acesso da experiência do estar doente ou de ter que conviver com uma doença que muita das vezes possui sinônimo de morte, facilitando assim o tratamento por fortalecer 0 vínculo enfermeiro-paciente, família e também por melhorar o relacionamento da equipe multidisciplinar de saúde.

\section{Esse cuidado surte efeitos?}

Nesse quadro a primeira ideia central apresentada revela que as orientações de enfermagem contribuíram para o alivio e melhora dos efeitos colaterais. Sabe-se que frequentemente, a pessoa portadora de câncer vivencia situações de medo, angústia e desespero, condições estas que devem ser previstas e, para as quais, os profissionais de enfermagem que estão em contato direto com estes pacientes devem estar preparados.

Quadro 6 - As orientações de enfermagem contribuem para a melhora/alivio dos efeitos colaterais?

\begin{tabular}{|c|c|}
\hline Ideia Central & Discurso do Sujeito Coletivo \\
\hline (1) Sim & $\begin{array}{r}\text { Sim, as orientações da equipe de enfermagem me ajudaram muito } \\
\text { e como ajudou. (...) Se elas trabalhassem apenas medicando e não } \\
\text { falassem nada, mas elas nós orientam muito, tiram as nossas duvidas, } \\
\text { são muito acolhedoras. (...) Melhorar ou aliviar os efeitos colaterais eu } \\
\text { acho que não, mas as orientações que elas passam ajuda muito, nos } \\
\text { deixa mais alerta para as coisas que podemos ou não fazer. }\end{array}$ \\
\hline (2) Mais ou Menos & $\begin{array}{r}\text { Mais ou menos, pois melhorar ou aliviar os efeitos colaterais isso não } \\
\text { aconteceu comigo, mas as orientações que elas passaram me ajudou } \\
\text { muito, pois me deixou mais alerta para as coisas que eu poderia ou não } \\
\text { fazer e sentir. (...) Não necessariamente alivia e nem melhora, mas elas } \\
\text { informam que irão surgir essas coisas. }\end{array}$ \\
\hline
\end{tabular}

Fonte: Informações provenientes dos participantes dessa pesquisa, ano 2013.

Deste modo, durante o processo de quimioterapia é de fundamental importância que se estabeleça com o paciente, um relacionamento de ajuda e confiança, que favoreça o esclarecimento de dúvidas, conversas a respeito das expectativas do tratamento e a expressão de sentimentos positivos e negativos.

Autores $^{17 ; 18}$ ressaltam que as relações com os pacientes não estão restritos apenas aos procedimentos técnicos, mas também podem compreender tributos típicos de uma relação de amizade, como abraços, carinhos e conversas confiáveis, revelando assim, que o cuidado de enfermagem não está limitado a determinados procedimentos técnicos, inclui ainda aspectos emocionais, morais, cognitivos e intuitivos.

Do mesmo modo, quando a equipe de enfermagem se envolve com as pacientes e com as suas famílias, valorizando os sentimentos e as emoções das mesmas, orientando-os e advertindo-os, abre-se a possibilidade de transformar 0 processo do tratamento, que é causador de medo e ansiedade, em algo menos desconfortável e nesse processo, a abertura do diálogo favorece o desenvolvimento das orientações adequadas sobre o tratamento e a patologia, tornandoos ativos no processo de autocuidado'.

Portanto, fica evidenciada a importância das orientações no processo do cuidado e da assistência de enfermagem durante um tratamento desgastante como a quimioterapia.

\section{Considerações Finais}

Percebe-se que o câncer enquanto doença crônica e multifatorial afeta tanto o portador da doença quanto seus familiares por induzir nestes, sentimentos desde o temor do diagnóstico, a expectativa do prognóstico até a possibilidade de cura ou de morte. E nesse processo que a quimioterapia enquanto tratamento é utilizado, pois pode reduzir ou erradicar as células cancerígenas. No entanto, a mesma geralmente é traumática por acarretar varias reações adversas, devido aos compostos químicos utilizados. 
Assim, percebe-se que o objetivo do estudo foi alcançado, pois se evidenciou a percepção das mulheres em quimioterapia sobre os cuidados de enfermagem aos efeitos adversos deste tratamento. Os relatos mostraram que a maioria destas sentem-se ruins e péssimas por terem algumas reações ao realizarem a quimioterapia. Revelaram ainda, sentirem dores, desânimo, sonolência, fadiga, náuseas, vômitos e dificuldade na aceitação da autoimagem. No entanto, diante da conduta realizada pelos enfermeiros frente aos efeitos colaterais, as participantes afirmam de forma unanime que a categoria de enfermagem orienta quanto às questões alimentares, proteção do corpo, quanto à frequência á ambientes fechados e os medicamentos recomendados sobre prescrição médica.

Diante do exposto observa-se a importância das orientações desenvolvidas nas consultas de Enfermagem para um melhor enfrentamento das reações adversas e efeitos colaterais do tratamento quimioterápico e consequentemente, melhorar a qualidade de vida das pacientes submetidas à quimioterapia.

No entanto, percebe-se que o enfermeiro por ser o profissional que na maioria das vezes está intimamente ligado a este processo, o mesmo deve constantemente buscar somar esforços com os demais profissionais, assim como, recorrer à capacitação continua e habilidades na comunicação para atender com eficiência e eficácia de forma humanizada.

Ressalta-se que é de real importância aplicar na prática clínica instrumentos que viabilizem um conhecimento acerca dos efeitos colaterais da quimioterapia, e que tal instrumento deve ser atrativo e estimulante. Sendo assim, foi elaborada uma cartilha junto com a equipe do Centro de Oncologia e Hematologia onde contemplou os diversos efeitos colaterais e as principais estratégias que poderiam ser realizadas pelas mulheres e pela equipe de enfermagem, para a redução ou alivio desses efeitos, ou seja, partiu-se do pressuposto de que a educação em saúde é a chave para a mudança na qualidade de vida dessas mulheres, cujo objetivo primordial seria tornar a paciente consciente e ativa no controle dos efeitos colaterais advindas da quimioterapia.

O intuito principal desta cartilha é contribuir com orientações para a redução/alívio dos efeitos colaterais da quimioterapia. Ressalta-se ainda, que é importante a disponibilização de um número telefônico destinado para as mulheres que realizam quimioterapia para entrarem em contato com a instituição e venham a retirar algumas dúvidas no que se refere ao surgimento dos efeitos colaterais e como tratá-los.

Salienta-se que este estudo propiciou um estímulo a ampliar os conhecimentos na área, fortalecendo uma visão mais ampla sobre a oncologia, especificamente, os efeitos colaterais advindas da quimioterapia no universo feminino.

No entanto, se reconhece as limitações deste trabalho e compreende-se que mais estudos relacionados a essa temática devam ser realizados, uma vez que o mesmo provoca muitas discussões.

\section{Agradecimentos}

Agradeço ao Centro de Oncologia e Hematologia no qual pesquisou-se, por ter oferecido espaço, disponibilidade e incentivo necessário para a construção deste trabalho, pois é através da sua brilhante inciativa, que vem fazendo a diferença na assistência à saúde, ensino e pesquisa da nossa cidade.

Meu muito obrigado a todos que de alguma maneira contribuíram para a execução desse trabalho, seja pela ajuda constante ou por uma palavra de amizade!

\section{Referências Bibliográficas}

1. Bonassa EMA. Enfermagem em Terapêutica Oncológica. $4^{a}$ ed. São Paulo (SP): Editora Atheneu; 2012.

2. Ministério da Saúde (BR). Instituto Nacional do Câncer: Incidência de Câncer no Brasil - Estimativa de 2012. Ministério da Saúde; 2012.

3. Conceição LL, Lopes RLM. O cotidiano de mulheres mastectomizadas: do diagnóstico à quimioterapia. Ver enferm UERJ. 2008; 16: 26-31.

4. Anjos ACY, Zago MMF. A experiência da terapêutica quimioterápica oncológica na visão do paciente. Rev Latino-am Enfermagem. 2006; 14: 33-40.

5. Minayo MCS. Pesquisa social: teoria, método e criatividade. 22 ed. Rio de Janeiro: Vozes; 2008.

6. Polit DF, Beck CT, Hungler BP. Fundamentos de pesquisa em enfermagem. Métodos, avaliação e utilização. 5 ed. Porto Alegre: Artmed; 2004. 
7. Lefèvre F, Lefèvre AMC. O sujeito coletivo que fala. Comunicação, Saúde, Educação. 10 ed. Jul/Dez; 2006.

8. Adami H, Hunter D, Trichopoulos D. Textbook of Cancer Epidemiology. 2 ed. Oxford University Press; 2008.

9. Camargo MC, Marx AG. Reabilitação física no câncer de mama. São Paulo: editora Roca; 2004.

10. Sales CA, Molina MAS, Cardoso RCS. Estar com um ente querido com câncer: concepções dos familiares. Nursing. 2006; 97 (8), 878- 882.

11. Silva RCF, Hortale VA. Rastreamento do Câncer de Mama no Brasil: Quem, Como e Por quê?. Revista Brasileira de Cancerologia. 58 ed:67-71; 2012.

12. Guimarães AGC, Anjos ACY. Caracterização Sociodemográfica e Avaliação da Qualidade de Vida em Mulheres com Câncer de Mama em Tratamento Quimioterápico Adjuvante. Revista Brasileira de Cancerologia, 2012; 58(4): 581-592.

13. Brasil, Ministério da Saúde. Instituto Nacional de Câncer. Cuidados paliativos oncológicos: controle da dor. Rio de Janeiro: INCA, 2001.

14. Frigato $\mathrm{S}$, Hoga LAK. Assistência à mulher com câncer de colo uterino: o papel da enfermagem. Rev. Bras de Cancero, 2003, 209-124.

15. Souza MGG, Santo FHE. O Olhar que olha o outro. Um estudo com familiares de pessoas em quimioterapia antineoplásica. Revista brasileira de cancerologia 2008; 53 (1): 31-41.

16. Gonçalves LLC, et al. Mulheres com câncer de mama: ações de autocuidado durante a quimioterapia. Rev. enferm. UERJ, Rio de Janeiro, 2009 out/dez; 17(4):575-80.

17. Alfaro-Lefevre R. Aplicação do Processo de Enfermagem: um guia passo a passo. 5.ed. Porto Alegre: Artmed, 2005.

18. Fontes CAS, Alvim NAT. Human relations in nursing care towards cancer patients submitted to antineoplastic chemotherapy. Acta paulista de enfermagem 2008; 21(1):77-83.

\section{Leonardo Magela Lopes Matoso}

Endereço para correspondência - Rua: Elis Regina, n 170, Bairro: Abolição IV, CEP: 59614-100, Mossoró, RN, Brasil.

E-mail: leonardo.I.matoso@gmail.com

Lattes: http://lattes.cnpq.br/2525968153754172

Sâmara Sirdênia Duarte de Rosário - sirdenia.dr@hotmail.com

Mônica Betania Lopes Matoso - monicabetania@yahoo.com.br

\section{Enviado em 06 de outubro de 2013. Aceito em 13 de agosto de 2015.}

